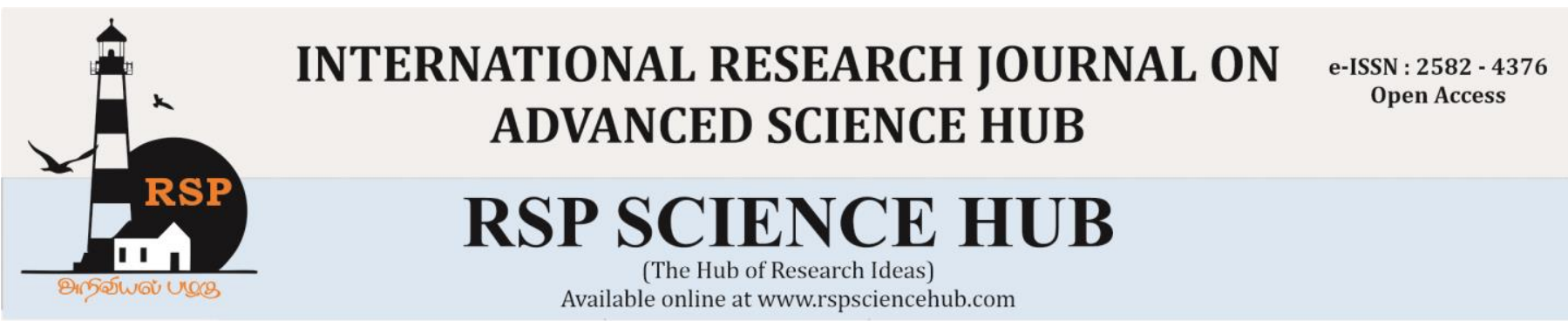

\title{
Arthroplasty Advancement: Remodification Design of Total Hip Replacement
}

Nirsandh.G $G^{1}$, Preetha. $S^{2}$, Sabeer yaccob ${ }^{3}$,

${ }^{1,2,3}$ UG Scholar, Department of Biomedical Engineering, Karpagam Academy of Higher Education.

Tamilnadu, India .

nirshanthkodai@gmail.com1

\begin{abstract}
Bio implants are getting progressively significant in the cutting edge society because of the reality of a maturing populace and related issues of osteoporosis and osteoarthritis. Bio-embed area is required to confront a monstrous development in up and coming year. Although a standardized hip joint corrective could be simple resolution to repair most diseases connected to hip joint, it never satisfies the patient's personal needs due to the distinctiveness of human anatomy. Update hip substitution alludes to the procedure to re-establish or supplant a bombed hip substitution. In the course of recent years, general hip substitution has risen as one of the most basic surgery to return sufferers to energetic, contributing people of society. The careful tasks to refresh the exhausted, excruciating hip with prosthetic segments (essential all-out hip substitution) has been led on a large number of patients with wonderful victories with typical barely any entanglements. Generally speaking, a hip option is quickly transforming into an activity sought after by utilizing a mid-ways of life individuals, despite everything working patient populaces who request high highlights and solid mechanical properties to accomplish a particularly energetic way of life.
\end{abstract}

Keywords: Total hip replacement, bio implants, osteoarthritis, redesign.

\section{Introduction}

The need for vital tissues and organs for transplantation is noted to be high. Implants which is required for replacing for the organs in human body are called bio-implants. Aseptic loosening, stress shielding and replacement fracture includes in the THA complexity. Even in a good hip arthoplasty significant peripheral implant bone reabsorption occurs a debris THA surpasses $95 \%$ over multi year. $15 \%$ updates happen under 5 years alternate model of the linear and shell may reduce the joint stiffer. Bone remodel occurs in which bone gets reabsorbed and loses mass, which known as stress shielding. We focus in modification / redesign the current model hip implant by using a CAD (Computer Aided Design) design and simulated by using ANSYS tool. Testing is done using FEM simulation in order to evaluate the mechanical strength of the product using modules of elasticity, tensile strength, hypothesis, Fatigue strength, surface tension, stress concentration.

\section{Artificial hip joint}

Replacing portions of a hip joint, for example, the femoral head that gets inadequate because of neurotic modification or mishap by an arthroplasty or a substitution gadget, returns to the nineteenth century [7]. These days around 200,000 and 80,000 mediations/year are acted in the USA and in the UK, individually, and they are evaluated to climb about $170 \%$ by 2030 . Albeit hip arthroplasty is viewed as probably the best accomplishment in an orthopaedic medical procedure in the most recent decades, from a designing perspective hip inserts are not a total achievement and still need further advancements. 
Specifically, they will, in general, they have a constrained assistance life of around 15 years [6]. The essential guideline of THR is, the inadequate hip joint is supplanted by a false acetabular cup and femoral head, which supplant the harmed characteristic bone. In this manner, the embed must have low rubbing and withstand wear and mechanical burden. The femoral head is appended to the femur by the stem. The acetabular cup is joined in the pelvis and is made out of a shell where a liner is embedded that gives the heap bearing to the articulating surface [7].

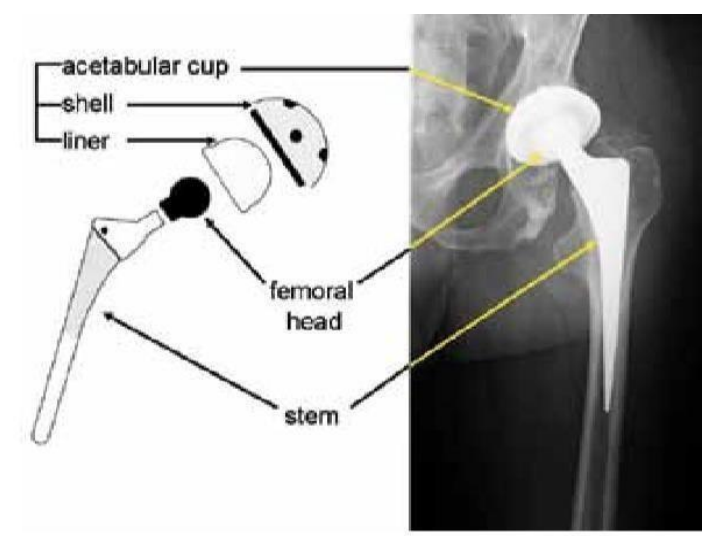

Fig 1.1 Segments of a hip arthroplasty

\section{Optimized design}

The main aim behind the optimized design implementation is to design an arthroplasty to prevent dislocation of the femur head from the acetabular cup of replacement after surgery, to Modify the design so that there is no tissues growth inside the arthroplasty which causes joint stiffening and to implement an arthroplasty so that the arthroplasty can be made is a customized way which can bear more stress and load.

\subsection{Acetabular cup modification}

The acetabular cup is to be redesign in a method of semi circled shape. Improvement in the value and size of the shell design is to prevent the growth of tissues inside the acetabula cup. Standard size of the shell is $56 \mathrm{~mm}$ average. Our design is to increase the diameter of the Linear and to prevent the extra tissue growth inside the acetabula cup surface. Redesign the shell with adding pattern like structures and knurling's which will make some extra grip to the hip bone as well as natural Bone. This condition makes fixation of the acetabula cup without Cement.

\subsection{Stem modification}

Redesign the stem so that the material conception is less. Construction, designing and methodology for the prosthesis by using topology optimization and lattice optimization using optistruct. Optimizing the solid lattice implant is to reduce stress shielding effect efficiently and satisfy ISO fatigue requirements

\section{Material selection}

Determined selection of the implantable biomaterial is the primary factor for the long period achievement of implants. The human body did not aware of any remote material so to limits the biologic presentation, an embed ought to be chosen to decrease the negative biologic reaction while keeping up the vital function [1]. The principal configuration issue is the material choice for the best biocompatibility and adequate mechanical quality. Biocompatible polymer and clay platforms, (for example polyethylene) have been broadly utilized as arthroplasty components [2]. The mechanical properties of the polymer platforms are deficient to help bone development under stacking conditions, and the fired frameworks are extremely weak. A couple of metal platforms, for example titanium and tantalum froth can give enough quality and weakness obstruction since they keep up adequate mechanical quality and weariness opposition [3].

\subsection{Titanium}

Titanium has extraordinary exertion and consumption interference. An ordinary titanium combination of Ti-6Al-4V, highlights a yield quality $900 \mathrm{mpa}$, extreme lastingness $960 \mathrm{mpa}$, and a versatility modulus $110 \mathrm{gpa}$, titanium composites are three structures alpha, beta, and $\alpha-\beta$. These sorts start when unadulterated titanium is warmed with the component of al, VA in specific focuses and chilled off, these additional components played as the stage of condition stabilizers. Aluminum is an alpha-stage condition stabilizer and it additionally builds the quality and decreases the heap of the combination. Vanadium goes about as a beta-stage stabilizer. Temperatures to which the predefined structure is available are regularly gotten by bringing composite at temperature. To broaden the 
quality, these amalgams could likewise be blessed to receive heat. The first regular titanium combination contains $6 \%$ al and4\% VA (ti6 al $4 \mathrm{v}$ ) $[8,9]$. Be that as it may, the drawback of this composite is its poor protection from wear, and score affectability when utilized as bearing material [4]. Tantalum carbide covering might be a decent technique for protecting hard coatings against wears in sliding applications; accordingly, a layer of tantalum carbide covering $(780 \pm 50 \mathrm{~nm}$ thick and $53 \pm 4 \%$ carbon content) could likewise be applied to the articulating surfaces to downsize the mileage. [5]

\section{Mechanical Property Analysis}

As far as the bio compactability of the arthroplasty is concerned the mechanical properties is also important. The design of the arthroplasty shouldbe strong such that it withstand the stress and strain applied on the implant, the elasticity of the implant. To analyse these properties testes such as finite element analysis, young's modulus of elasticity, fatigue analysis should be done

\subsection{Finite Element Analysis}

FEA examination is finished by the replication condition of ansys programming. The 3D model structured by CAD Software is tried for its mechanical properties in Ansys Software. A limited component investigation gives incitement for any gave physical factors utilizing scientific files. Issues are unravelled utilizing differential conditions utilizing a few factors. FEM is to make those huge frameworks, straightforward parts so it is called Finite component Analysis. Rough Order of Magnitude Estimate (ROM estimate) is a perception degree of project completion. Presentation of ROM is contribute to make a conclusion of effort level is to create discretion to move forward with hinge on project, in a title of cost and duration. [16]

\section{3D Metal Printing}

The goal of the paper is to prove the design remodification of hip implant production from the computed tomography surgeon was performed. This process converts the computed tomography files to computed aided design. [10]

\subsection{Advantages}

$\mathrm{AM}$ is the additive manufacturing technique of metal fabrication AM can be used to form shape which could not be performed in any other method. AM allows corrosion resistance and higher stress materials for printing.AM widely used in medical implant production faster developing $\mathrm{AM}$ is to promote the strength of the implant. [11]. AM technology is developing the operation and production necessity of net structures. This technology allows the human bone visualization in a 3D format. Computed tomography is the diagnostic equipment used by the clinicians to identify the hard tissue related issues. In production pathway 3D is the first criteria[12].

\section{Table.4.1. Comparison Table of FEM Analysis}

\begin{tabular}{|c|c|c|c|c|c|}
\hline FEAANALYSSS & $\begin{array}{c}\text { TIDDER } \\
2005 \\
{[11]}\end{array}$ & $\begin{array}{c}\text { YOSIME } \\
2006 \\
{[18]}\end{array}$ & $\begin{array}{c}\text { PATEL } \\
\& \\
\text { GOSTALI } \\
2012 \\
{[19]}\end{array}$ & 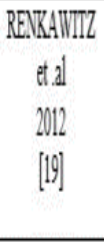 & $\begin{array}{c}\text { OCR } \\
\text { PAPER }\end{array}$ \\
\hline Flexion & $130^{2}$ & $110^{\circ}$ & $122^{*}$ & $130^{\circ}$ & $120^{*}$ \\
\hline Extersion & $40^{*}$ & $30^{*}$ & $17^{k}$ & $40^{x}$ & $35^{*}$ \\
\hline Aboction & $50^{*}$ & . & $43^{*}$ & $50^{*}$ & $50^{8}$ \\
\hline Addection & $50^{*}$ & $\cdot$ & $40^{*}$ & $50^{*}$ & - \\
\hline $\begin{array}{l}\text { Extemal } \\
\text { Rotition }\end{array}$ & $40^{*}$ & $4 x^{x}$ & $30^{*}$ & $40^{x}$ & $40^{x}$ \\
\hline 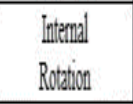 & $80^{*}$ & . & $60^{*}$ & $80^{*}$ & . \\
\hline 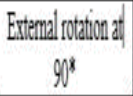 & . & . & . & . & . \\
\hline 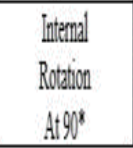 & . & $30^{4}$ & . & . & $50^{8}$ \\
\hline
\end{tabular}

Table.4.2 Parameters of ROM Analysis

\begin{tabular}{|l|c|}
\hline \multicolumn{1}{|c|}{ PARAMETERS } & $\begin{array}{r}\text { MECHANICAL PROPERTIES } \\
\text { (ROUGH ORDER MAGNITUDE) }\end{array}$ \\
\hline $\begin{array}{l}\text { Head Diameter } \\
\text { (Head to Neck) }\end{array}$ \\
\hline Theoretical Femoral Stem & \\
\hline Neck Diameter & \\
\hline Cup and Stem Orientation & \\
\hline
\end{tabular}

Table.4.3 Range value of Parameters and Functions 


\begin{tabular}{|l|l|}
\hline \multicolumn{1}{|c|}{ PARAMETER FUNCTION } & \multicolumn{1}{c|}{ RANGE } \\
\hline HEAD DIAMETER & $20 \mathrm{~mm}$ \\
\hline NECK DIAMETER & $14 \mathrm{~mm}$ \\
\hline HEAD TO NECK RADIO & $(1.65,4.25)$ \\
\hline MAXIMUM ANGLE OF RADIUS & $180^{*}$ \\
\hline OSCILLATION ANGLE & Functional head/neck diameter, A. \\
\hline CUP ANTERVERSION & $16.26^{*}$ \\
\hline CUP INCLINATION & $42.77^{*}$ \\
\hline STEM ANTETORSION & $30.37^{*}$ \\
\hline STEM OFFSET & 42,45 \\
\hline FLEXION & $120^{*}$ \\
\hline EXTENSION & $35^{*}$ \\
\hline NNTERNAL ROTATION AT 90 DEGREE & $50^{*}$ \\
\hline EXTERNAL ROTATION AT 90 DEGREE & $40^{*}$ \\
\hline ABDUCTION & $50^{*}$ \\
\hline
\end{tabular}

Table.6 Final output value of optimised model

\begin{tabular}{|c|c|c|c|}
\hline VALUES & $\begin{array}{c}\text { D'LIMA et.al } \\
\text { [21] }\end{array}$ & $\begin{array}{c}\text { OPTIMIZED } \\
\text { DESIGN }\end{array}$ & CHANGE (\%) \\
\hline Head diameter & 32 & 32 & N.A \\
\hline Neck diameter & 12.25 & 14.71 & N.A \\
\hline Head to neck ratio & 2.61 & 2.17 & N.A \\
\hline Oscillation argle (DEG) & 135.0 & 88.2 & 33.6 \\
\hline Flexion & 139.9 & 132.6 & .5 .3 \\
\hline Exersion & 42.9 & 35.6 & -17.1 \\
\hline Extemal rotation & 49.7 & 40.8 & .17 .9 \\
\hline $\begin{array}{l}\text { Internal } \\
\text { Rotation } \\
90^{8} \text { fexion (DEG) }\end{array}$ & 57.3 & 50.4 & -12.0 \\
\hline $\begin{array}{l}\text { Principal stress } \\
(\mathrm{MPA})\end{array}$ & 132.7 & 88.2 & 33.6 \\
\hline Abduction & 59.3 & 53.3 & -10.2 \\
\hline
\end{tabular}

\section{Conclusion}

This project will result in an efficient hip arthroplasty replacement. The usage of titanium alloy will be more bio compactable compared to other material. The additive manufacturing 3D printing gives an opportunity to design a customised arthroplast using CT images. The strength of the arthroplast is increased due to 3D manufacturing technique.

\section{Future Work Bioprinting}

The future scope of project involves in bio printing. To manufacturing an arthoplasty used to create model like human bones that flattering natural hip joint.Bioprinting is the additive of cells, cellular growth functions, and biomimetic to inventing bio medicinal parts that maximally replicate tissue functions.3D printing make use of layer by layer deposition of bio ink to made cellular tissue like shape to use for the tissue engineering domain. The scaffolds used to revival of joints. In addition, 3D bio preparation has begun the embodiment of scaffolds printing. [13]

\section{References}

[1] Saini M, Singh Y, Arora P, Arora V, Jain K. Implant biomaterials:

A comprehensive review. World J Clin Cases. 2015 Jan 16;3(1):52-7.

[2] Design of a graded cellular structure for an acetabular hip replacement component Hongqing Vincent Wang a R\&D Engineer Scott R. Johnston b Postdoctoral Fellow David W. Rosen b*

a. Professor a ironcad Inc., 700 Galleria Parkway, Suite 300, Atlanta, GA

b. 30339 b The George W. Woodruff School of Mechanical Engineering, Georgia Institute of Technology Atlanta, GA 30332

[3] J.-P. St-Pierre, M. Gauthier, L.-P. Lefebvre, and M. Tabrizian, "Threedimensional growth of differentiating MC3T3-E1 preosteoblasts on porous titanium scaffolds," Biomaterials, vol. 26, pp. 7319-7328, 2005.

[4] H. Agins, N. Alcock, M. Bansal, E. Salvati, P. Wilson, P. Pellicci, and P. Bullough, "Metallic wear in failed titanium-alloy total hip replacements. A histological and quantitative analysis," The Journal of Bone and Joint Surgery, vol. 70, pp. 347-356, 1988. 